Research Paper

\title{
Thermal performance of different exterior wall structures based on wall orientation
}

\author{
Tugce Pekdogan*, Tahsin Basaran \\ Department of Architecture, Izmir Institute of Technology, İzmir, Turkey
}

\section{H I G H L I G H T S}

- Insulation location effect in the transient heat conduction problem was studied.

- Insulation thickness effect was studied for different climatic regions in Turkey.

- Different facade orientations were investigated.

- 1-D transient heat conduction was solved by implicit finite difference method.

\section{A R T I C L E I N F O}

\section{Article history:}

Received 25 May 2016

Revised 6 October 2016

Accepted 10 October 2016

Available online 13 October 2016

\section{Keywords:}

Thermal insulation

Insulation thickness

Insulation location

Wall orientation

\begin{abstract}
A B S T R A C T
Heat transfer from opaque walls of buildings is very important for energy saving and providing thermal comfort in different climates. In this study, insulation models of opaque walls with different orientations and external, internal and sandwich materials were numerically analyzed in terms of their timedependent thermal behaviors. The one-dimensional transient heat conduction equation was solved via the implicit finite difference method for summer and winter conditions and northern, southern, eastern and western orientations. Meteorological data for cities in Turkey with different climates, i.e., Ankara, Erzurum, İstanbul and İzmir, were used in these calculations. When the outside boundary conditions were defined by using January and July monthly averages of the daily data; the inside air temperature was assumed to be $20^{\circ} \mathrm{C}$ and $24^{\circ} \mathrm{C}$ in winter and summer. The results indicated that sandwich wall insulation produced more convenient heat loss and heat gain for each climate and direction. The standard deviations of the heat transfer values for the different directions were larger in summer than in winter because of the solar radiation effect. The numerical calculations for the sandwich wall applications were carried out for different insulation thicknesses namely $0.15 \mathrm{~m}$ and $0.25 \mathrm{~m}$, and for an uninsulated wall; the results were also compared with Turkish directive on the thermal insulation of buildings, TS 825 taken as a reference condition. Compared with the insulation thickness calculated based on the TS825, the heat loss and gain values could be decreased by up to $65 \%$ and $80 \%$ for the worst winter and summer conditions.
\end{abstract}

(c) 2016 Elsevier Ltd. All rights reserved.

\section{Introduction}

The application of heat insulation in the walls of buildings is one of the most significant factors within the entire set of policies related to global energy efficiency. Because approximately $40 \%$ of total energy consumption is associated with the building sector, growing interest has been witnessed in the form of studies related to heat insulation in the building sector in the European Union

\footnotetext{
* Corresponding author at: İzmir Institute of Technology, Department of Architecture, 35430 Urla/İzmir, Turkey.

E-mail addresses: tugcepekdogan@iyte.edu.tr, tahsinbasaran@iyte.edu.tr (T. Pekdogan).
}

(EU). In Turkey, the building sector constitutes a considerable share of energy consumption; hence, giving precedence to energy efficiency in the building sector is recommended. The use of energy and the development and application of advanced thermal insulation systems is expected to provide an advantage for other sectors as well. Providing acceptable applications for the effective use of energy and thermal insulation systems should be recognized as one of the most important objectives of sustainable buildings. Opaque building faces play a significant role in improving thermal comfort and reducing energy consumption. Many studies have addressed optimal insulation thickness depending on either heating or cooling loads. Some authors [1-17] have calculated the loads for different climatic conditions. Insulation thickness has also been 
coupled with various aspects such as insulation material type, climatic condition, orientation and life cycle cost analysis under steady state conditions [1-7] or transient conditions [8-17]. Steady state analysis is not given appropriate results compared with the transient solution, since the thermal mass effect is not considered in the calculations. These studies [1-7] are different from the current study. Some investigated the optimal insulation thickness on the exterior walls with respect to the different regions $[1,2,6,7]$. Some investigated insulation materials [3,4], and one investigated the effect of insulation thickness using life cycle analysis [5]. Refs. [8-17] used the time-dependent approximations were introduced in this study which included the numerical solutions of the onedimensional time-dependent heat conduction equation by using the finite difference method of the partial derivative terms.

Daouas et al. [8] investigated optimal insulation thickness for building walls in Tunisia using the one-dimensional timedependent heat conduction equation. A life-cycle cost analysis was carried out using two types of insulation materials and two typical wall structures. Yumrutaş et al. [9] used the complex finite Fourier transform method to find the total equivalent temperature difference values of the building envelope including the roof and walls. This paper also described the calculation of hourly heat gains and inner surface temperatures for a 24-h time period of one representative summer day for three types of wall structures with and without insulation. Al-Sanea and Zedan [10] considered the impact of insulation location on the heat transfer of the building wall structure. They demonstrated that the insulation layer position influenced the immediate and daily mean loads under transient conditions.

The effect of insulation location on the heat transfer characteristics of the building envelope and optimization of insulation thickness have been investigated in many studies using the finite difference method. Ozel [11] used an implicit finite difference method under periodic conditions to investigate the effect of insulation location and thickness. The results indicated that the insulation location has an important effect on the annual averaged time lag and decrement factor. The maximum temperature fluctuations and peak load occurred in the case where insulation was placed in the middle of a wall, whereas outside insulation produced the smallest fluctuations. In another study [12], the thermal performance of insulation on an external wall was identified based on economic analysis under transient conditions on the south facade of a building using various materials in Elazığ, Turkey. The results indicated that the optimal insulation thickness for energy savings was $2-8.2 \mathrm{~cm}$. Ibrahim et al. [13] identified the usable exterior wall and the various combinations and positions of insulation layers within external walls and examined the heating and cooling loads of the buildings' exterior surfaces. These compositions for the outside wall used different materials; the insulating material was selected to be silica aerogels. The thermal behavior of the wall with the aerogel-based coating was investigated using experimental and numerical models. The optimal composition was found to be an insulation layer divided into two parts and placed in the middle of the wall with another part at the exterior surface. Gagliano et al. [14] studied the effect of thermal inertia combined with natural ventilation on a massive historical building wall. Numerical and experimental results showed the high potential of such combination (providing ventilation and thermal mass) to prevent overheating during summer, as mentioned in another study [15]. The thermal inertia of the walls depends on thermal properties such as thermal conductivity, specific heat and density. However, other parameters may also affect the thermal inertia of the building. The air change rate modifies the indoor temperature and, consequently, the thermal inertia. Axaopoulos et al. [16] studied the thickness of optimal insulation for outside multi-layer walls with different climatic conditions and considered wind direction and speed and orientations of building associated with different wall configurations in Athens, Greece. The annual heating and cooling loads were calculated using the transient heat transfer approach. The optimal insulation thickness for different wall composition were calculated for southern, western, eastern and northern orientations as $7.1,10.0,10.0$ and $10.1 \mathrm{~cm}$, respectively. Wati et al. [17] calculated the optimal insulation thickness of building exterior walls using the finite difference method with dynamic software. Energy savings and the payback period were also determined for a tropical zone as a function of orientation and incorporating the shading effect. The results showed that the shading level was inversely correlated with insulation thickness and that the eastern and western directions of the wall were associated with the highest energy saving values. Different from the other studies [1-17], heat transfer values through the exterior wall were given relatively considering different directions and varying $U$-values in this study. In addition, insulation position was evaluated under different climatic conditions based on the measurements of monthly averages of the daily data in January and July.

Based on these reports, in this study, one of the most important objectives was to investigate a wall structure for which the onedimensional, time-dependent heat conduction equation could be solved using the implicit finite difference method. The insulation position varied among the walls and included uninsulated, inside, outside, and sandwich insulation wall types. Insulation thickness was determined using the TS825 Directive on Thermal Insulation in Buildings [18] for different climatic conditions, and for each location of the thermal insulation material, the energy demand was computed individually using a customized Visual Basic program. The source of the data for the model developed in Visual Basic and the associated code was the temperature of four different cities in Turkey. The documents used were collected from the Turkish Ministry of Forestry and Water Affairs General Directorate of Meteorology [19]; the solar energy data were collected from the Photovoltaic Power Systems Program (PVPS) of the International Energy Agency (IEA) [20] for Ankara, Erzurum, İstanbul and İzmir in Turkey. Facade orientation is another important factor to determine the energy consumption of a building. The data were collected as functions of building orientation, i.e., south, west, north and east. According to these variables and to design a low-energy house with better energy performance than typical new buildings, two different $U$-values based on energy regulations and standards [21] were defined to reduce heating and cooling loads. The AECB (The Association for Environment Conscious Building) is a network for promoting sustainable building. There are three different categories in this standard for building energy consumption: Gold, Silver and Bronze [21]. These classifications are arranged based on $\mathrm{CO}_{2}$ emissions and predicted energy use. The exterior wall overall heat transfer coefficient (U-value) described as the Silver Standard is $0.25 \mathrm{~W} / \mathrm{m}^{2} \mathrm{~K}$; for the Gold Standard, it is $0.15 \mathrm{~W} / \mathrm{m}^{2} \mathrm{~K}$. These Uvalues were also considered in the heat loss and gain calculations, and the results were compared with each other.

\section{Problem definition}

In this study, three different situations were created with respect to the position of insulation materials under different climatic conditions (Fig. 1). These situations are as follows: uninsulated, inside, outside and sandwich insulated. As an envelope body element, $20 \mathrm{~cm}$ of concrete with inside and outside plaster was used, and XPS (extruded polystyrene foam) was employed as an insulation material; hence, heat gain and loss rates under different insulation situations could be computed. For the building envelope thermal insulation, the specific calculations were based on TS825 for four climatic zones with overall heat transfer coeffi- 


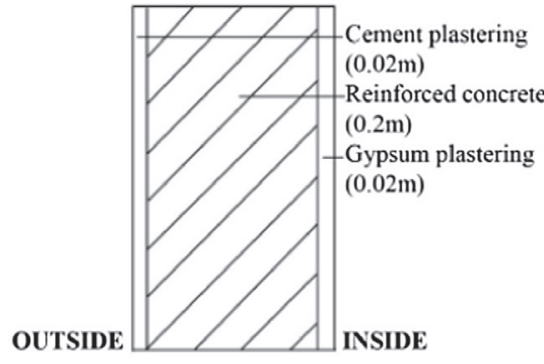

Uninsulated Wall

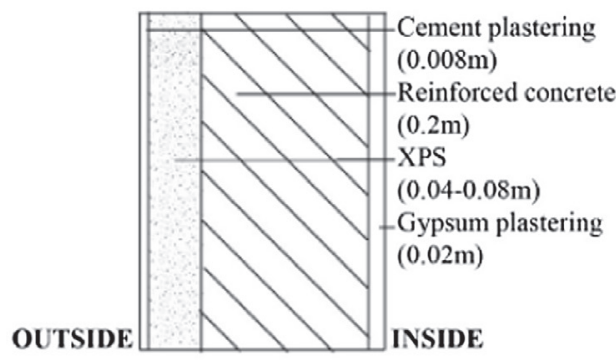

Exterior Wall Insulation

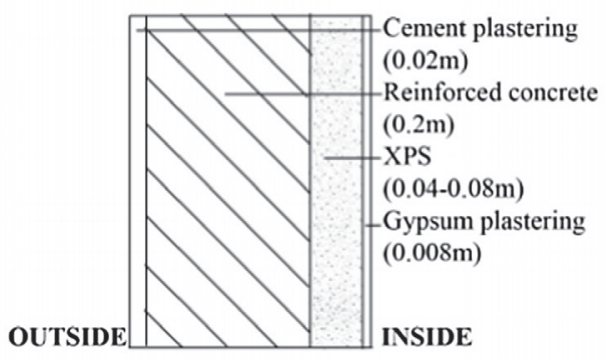

Interior Wall Insulation

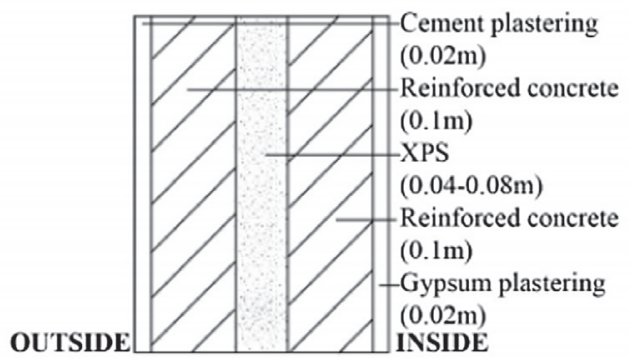

Sandwich Wall Insulation

Fig. 1. Schematic representation of multilayer wall types.

cient $\mathrm{U}$ values. The values $0.7 \mathrm{~W} / \mathrm{m}^{2} \mathrm{~K}, 0.6 \mathrm{~W} / \mathrm{m}^{2} \mathrm{~K}, 0.5 \mathrm{~W} / \mathrm{m}^{2} \mathrm{~K}$ and $0.4 \mathrm{~W} / \mathrm{m}^{2} \mathrm{~K}$ are the recommended values for İzmir, İstanbul, Ankara and Erzurum, respectively. Insulation thickness as a function of the given overall heat transfer coefficient value was also calculated. The thickness of applied insulation material was $0.04 \mathrm{~m}$, $0.05 \mathrm{~m}, 0.06 \mathrm{~m}$ and $0.08 \mathrm{~m}$ for İzmir, İstanbul, Ankara and Erzurum, respectively. The overall heat transfer coefficients were redefined and calculated using certain insulation thickness values.

The transient one-dimensional heat conduction equation in a multilayered wall with a total thickness $L$ without heat generation and for an isotropic and homogeneous layer is defined as

$k \frac{\partial^{2} T(x, t)}{\partial x^{2}}=\rho c_{p} \frac{\partial T(x, t)}{\partial t}$

where $t$ and $x$ represent the time and spatial coordinates, $T$ is the temperature, and $k, \rho$ and $c_{p}$ are the thermal conductivity, density and specific heat of the building materials, respectively. The boundary and initial conditions were assigned based on climatic conditions, and Eq. (1) was calculated using the formula given in Eqs. (1a)-(1d):

$$
\text { at } \begin{aligned}
x & =0, \text { for } t>0 \Rightarrow-k_{0} \frac{\partial T}{\partial x} \\
& =\alpha I+\sigma \varepsilon\left(T_{s k y}^{4}-T_{s, 0}^{4}\right)+h_{o}\left(T_{\infty, o}-T_{s, 0}\right)
\end{aligned}
$$

at $x=L$, for $t>0 \Rightarrow-k_{L} \frac{\partial T}{\partial x}=h_{i}\left(T_{s, L}-T_{\infty, i}\right)$

at $t=0,0 \leqslant x \leqslant L \Rightarrow T(x, 0)=T_{\text {initial }}$

It is assumed that there is no thermal contact resistance between the layers shown in Fig. 1. This condition can be expressed as follows:

$$
\text { at interface boundary, for } \begin{aligned}
t & >0 \Rightarrow\left(-k \frac{\partial T}{\partial x}\right)_{\text {Layer } 1} \\
& =\left(-k \frac{\partial T}{\partial x}\right)_{\text {Layer } 2}
\end{aligned}
$$

where $k_{0}$ and $k_{L}$ are the thermal conductivity of the outside and inside surfaces, which were different types of plaster. The parameters $k_{0}$ and $k_{L}$ were taken as $0.72 \mathrm{~W} / \mathrm{m} \mathrm{K}$ and $0.38 \mathrm{~W} / \mathrm{m} \mathrm{K}$. The other thermophysical properties and thicknesses of each wall layer materials required for this study are given in Table 1 [18,22].

The parameter $\alpha$ is the absorption coefficient of the outside surface radiation property and is assumed to be 0.4 . The parameter $I$ represents the solar radiation value. The solar radiation database was developed using the Photovoltaic Geographical Information System - Interactive Maps [23]. This interactive map data for the European subcontinent were developed using the solar radiation model r.sun and dedicated programs integrated into the GIS software GRASS [24]. The r.sun algorithms are based on equations published in the European Solar Radiation Atlas [25]. Global irradiance on a fixed vertical plane $\left(\mathrm{W} / \mathrm{m}^{2}\right)$ according to the orientations (east, south, west and north) were defined as the outside boundary conditions for the January and July monthly averages of the daily data in İzmir, İstanbul, Ankara and Erzurum. The west- and east-facing sides were asymmetric in time and slope inclination angle and were mirror images. Low-angle north-facing slopes were affected for only short periods in winter but mainly affected by diffuse solar radiation. For south-facing slopes, relatively higher values occurred in January. However, in summer, the east and west facing slopes experienced relatively higher peak values for all of the selected cities. South-facing facades in January received mostly direct solar radiation over the course of a day in comparison with summer.

The parameter $\sigma$ represented the Stefan-Boltzmann constant, which was taken as $5.67 \times 10^{-8} \mathrm{~W} / \mathrm{m}^{2} \mathrm{~K}^{4} ; \varepsilon$ was the emissivity of the outside surface, which was assumed to be 0.93 [26]. $T_{s, 0}$ and $T_{s, L}$ were the outside and inside surface temperatures, which were calculated numerically in the code. $T_{\infty, i}$ represented the inside air temperature and was assumed to be $20^{\circ} \mathrm{C}$ and $24^{\circ} \mathrm{C}$ in winter and summer, following January and July daily constant data obtained from ASHRAE Standard55, which indicated that this comfort range is specified as the operative temperature for human occupancy [22]. Additionally, $T_{\infty, o}$ was the outside air temperature corresponding to the monthly average of the daily data. Meteoro- 
Table 1

Thicknesses and thermophysical properties of the wall materials [18,22].

\begin{tabular}{|c|c|c|c|c|}
\hline Material name & Thickness (m) & Conductivity (W/m K) & Specific heat (J/kg K) & Density $\left(\mathrm{kg} / \mathrm{m}^{3}\right)$ \\
\hline Outside gypsum plastering & 0.008 and 0.02 & 0.720 & 840 & 1860 \\
\hline Insulation material XPS & $0.03-0.08$ & 0.035 & 1400 & 35 \\
\hline Reinforced concrete & 0.1 and 0.2 & 2.300 & 1000 & 2300 \\
\hline Inside gypsum plastering & 0.008 and 0.02 & 0.380 & 1090 & 1120 \\
\hline Total & $0.268-0.308$ & & & \\
\hline
\end{tabular}

logical data were used for the outside conditions for different cities in Turkey. $T_{s k y}$ was the effective sky temperature calculated using Eq. (2) [26]:

$T_{s k y}=T_{\infty, 0}\left(0.8+\frac{T_{d p}}{250}\right)^{0.25}$

$T_{\text {sky }}$ varied based on climatic conditions depending on time. The sky temperature was defined using the dew point temperature and outside air temperature in Eq. (2) [26]. The dew point temperature $T_{d p}$ in units of Kelvin is associated with the relative humidity and air temperature. $T_{d p}$ values were generated using January and July weather data and Eq. (2). The parameters $h_{o}$ and $h_{i}$ represent outside and inside convection heat transfer coefficients, and were taken as $25 \mathrm{~W} / \mathrm{m}^{2} \mathrm{~K}$ and $7.692 \mathrm{~W} / \mathrm{m}^{2} \mathrm{~K}$ in the calculations based on TS825 [18]. $T_{\text {initial }}$ was the initial temperature of the wall section and was applied as an initial condition to the meshed areas. After running the code, a new temperature distribution through the wall section was calculated. This is the new initial temperature distribution for the next iteration. In this study, iteration was performed until the highest ratio anywhere through the wall between the final value and the one prior to that was $0.5 \%$. Temperature values through the wall were defined using the calculated final loop results.

The heat conduction model of a cross-sectional area was analyzed using Visual Basic code for solving the abovementioned problem. This is a standard root-finding problem in this simulation environment. It has been solved numerically using the finite difference method of the partial derivative terms of the one-dimensional time-dependent heat conduction equation. The numeric solution provides the temporary variance of the temperature at every interior node of the wall, which is selected to have spacing $1 \mathrm{~mm}$ after controlling mesh size independency. Unknown temperatures were solved using the Thomas tridiagonal matrix algorithm with the above-described boundary and initial conditions for the plane wall [27].

\section{Results and discussion}

\subsection{Heat transfer for different insulation and direction configurations}

Figs. 2-5 presents daily total heat loss and gain through a $1 \mathrm{~m}^{2}$ surface with exterior, interior and sandwich wall type insulation locations based on one-day average measurements of monthly data in January and July. The insulation thicknesses were defined by the TS825 [18] thermal insulation requirements for buildings in Turkey. The TS825 optimal insulation thickness and calculated U-values for the four climatic zones are indicated. The figures also show the orientations of the opaque surfaces. The calculated results were denominated in $\mathrm{Wh} / \mathrm{m}^{2}$ day, which is a unit of energy transfer per square meter per day. The left column represents the winter heat loss results from January data in İzmir, İstanbul, Ankara and Erzurum; the right column shows the summer results based on July data.

Heat loss and gain daily average values per square meter of opaque surface under January and July conditions for İzmir are shown in Fig. 2. İzmir lies in a Mediterranean climate; summers are generally hot, and winters are temperate. In this zone, cooling loads are as important as heating demand. In fact, especially for building HVAC applications involving solar radiation from semi-transparent surfaces and internal thermal loads, the peak heat gain value can be significantly larger than the summer loads shown in Fig. 2. Heat loss and gain from the sandwich wall insulation type are relatively lower than exterior and interior insulation types for almost all directions. Heat loss for sandwich insulation change from $-142.3 \mathrm{~W} \mathrm{~h} / \mathrm{m}^{2}$ day to $-170.4 \mathrm{Wh} / \mathrm{m}^{2}$ day, and heat gain values are calculated to be between $87.1 \mathrm{~W} \mathrm{~h} / \mathrm{m}^{2}$ day and $109.3 \mathrm{Wh}$ / $\mathrm{m}^{2}$ day. Maximum heat loss and gain differences are approximately $6.8 \%$ and $5.6 \%$, compared with sandwich and exterior wall insulation types.

Fig. 3 represents İstanbul's heat loss and gain for different insulation and direction selections. İstanbul's climate can be consid-

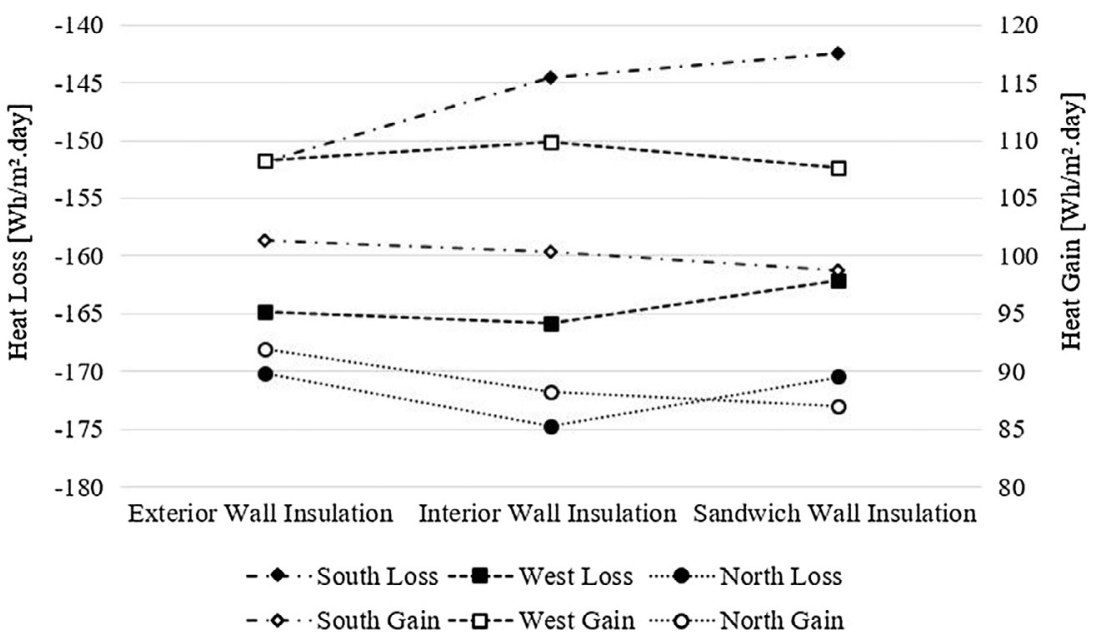

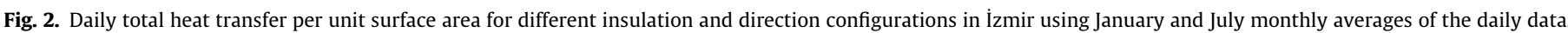




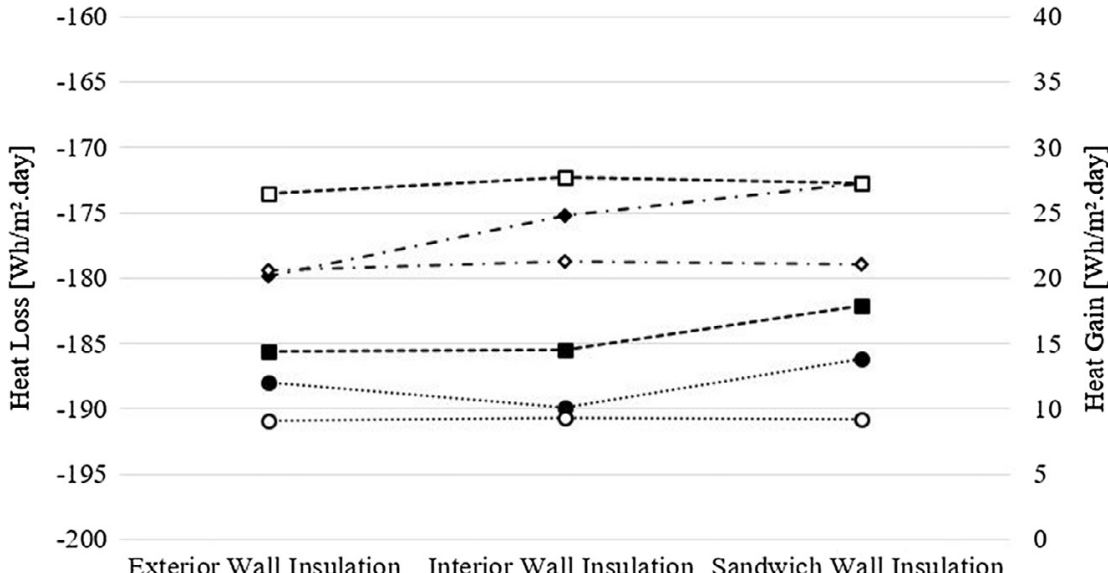

$$
\begin{aligned}
& \text { - } \downarrow \text { South Loss --r -- West Loss …… North Loss } \\
& \text { - } \diamond \text { South Gain -- } \square-- \text { West Gain ........ North Gain }
\end{aligned}
$$

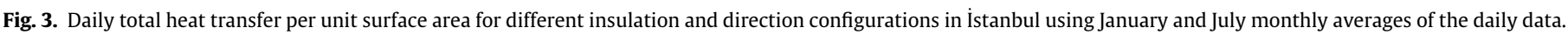

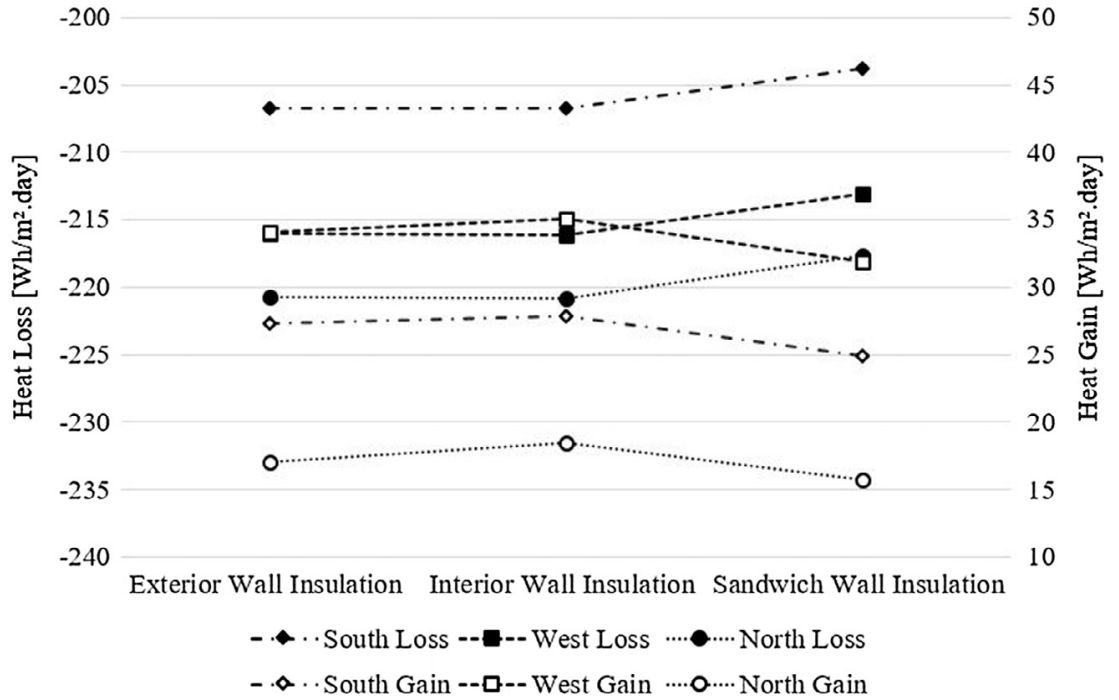

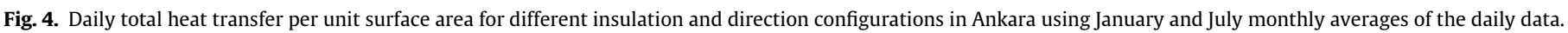
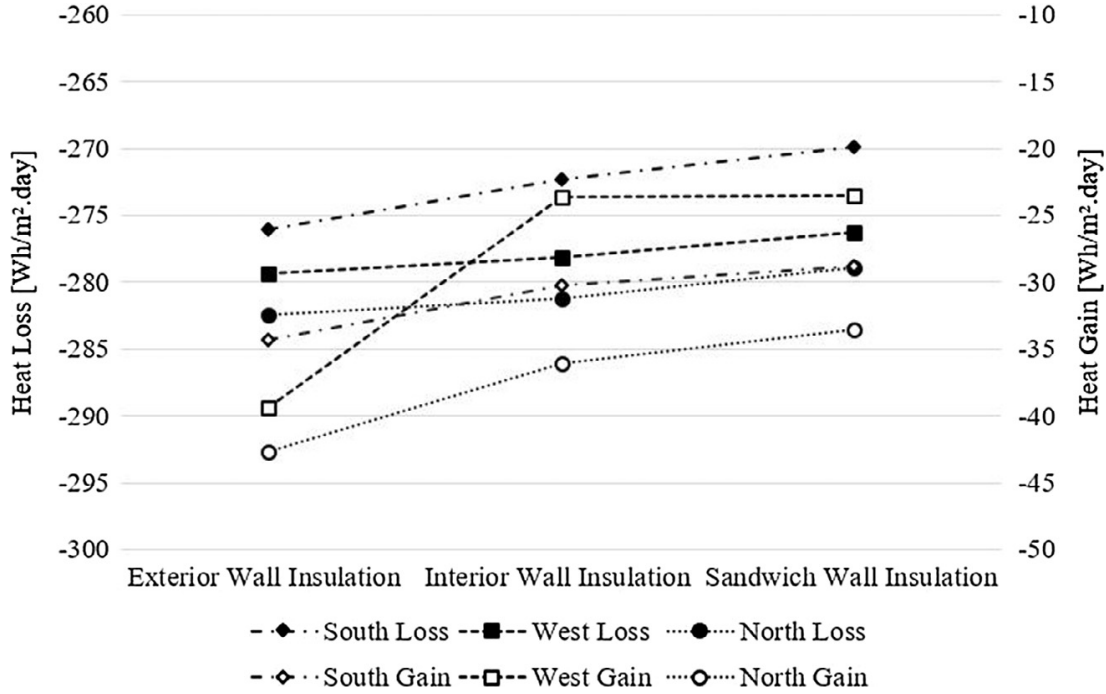

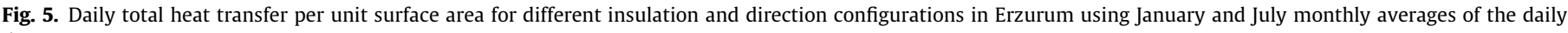
data. 
ered moderate; the temperature can drop below zero in the winter. There is minimal difference between the insulation types except for the south facade heat loss difference, which is approximately $4 \%$ between sandwich and exterior wall insulation types. The heat gain based on opaque surfaces drops sharply compared with İzmir's heat gain value because of the moderate summer conditions in İstanbul.

Heat loss and gain values for different configurations are presented based on weather data in Ankara, which is in a mild-dry zone in Turkey. Because the difference between day and night temperatures is high, heat gain values are larger than for İstanbul. Additionally, the heat loss values of Ankara are significantly larger than İzmir's and İstanbul's heat loss values as shown in Figs. 2-4. The sandwich type performs better than the other insulation types for all directions, and the difference can reach up to $2 \%$ in the winter.

Erzurum is in the cold climate zone; temperature values are below $0{ }^{\circ} \mathrm{C}$ for nearly half of the year, and the winters are long and harsh. In summer, heat loss occurs because the outside temperature is lower than the inside air temperature. This may change with internal heat gains and solar radiation from semi-transparent surfaces. It is vital for a cooling system to accommodate internal gain and solar radiation entering through the windows. The heat loss can be reduced by up to $2.6 \%$ using sandwich wall insulation.

The common message of Figs. 2-5 is that the total cooling and heating transmission loads are the lowest for the sandwich wall insulation type. However, the overall heat transfer coefficient of the sandwich wall insulation type is assumed to be lower than either the exterior or the interior types. These differences can be defined as $0.8 \%$ and $1.5 \%$. This difference occurs for different thicknesses of plaster applications as shown in Fig. 1. One advantage of the sandwich wall type arises from this relatively thicker plaster application ( $0.02 \mathrm{~m}$ thick plaster was used on both sides in the sandwich wall; $0.008 \mathrm{~m}$ thick plaster was used on one side for the other two applications).

According to the wall direction, the lowest heat gain is on the north-facing wall in the summer period. However, in the winter period, the maximum heat loss occurs from the north. The heating transmission loads are greater than the heat gain values for all orientations.

\subsection{Temperature distributions and heat transfer rates through the wall}

By running the code, the temperature distributions through the cross sections of the opaque walls were also obtained at different time steps for different wall configurations. The condensation problem can be checked between the layers of the composite wall, and the radiant temperature values of the indoor surface can also be controlled by considering the thermal comfort condition. The temperature distribution through the wall also provides an energy

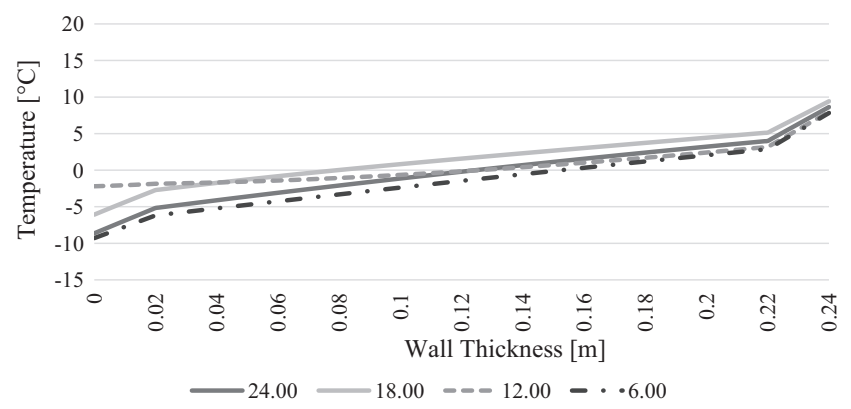

Fig. 6. Uninsulated wall temperature distributions through the wall at different times of the day for a south-facing wall in January in Erzurum. balance in the domain. Passive control strategies can be developed, and the heat transfer rates to and from the inside environment can be restricted.

Temperature distributions through the wall sections at different time steps for comparison of the uninsulated and sandwich insulation walls are given in Figs. 6 and 7. When the inside air temperature was set at $20^{\circ} \mathrm{C}$, the inside surface temperatures fluctuated between $7.8^{\circ} \mathrm{C}$ and $9.4^{\circ} \mathrm{C}$ for the uninsulated configurations in the winter in Erzurum. These radiant temperature values were insufficient to provide thermal comfort. However, sandwich wall insulation enabled nearly stable radiant temperatures that was close to the inside air temperature during the winter days, which satisfies the needs of this application. The sandwich wall insulation resulted in a lower heat loss value than the other two configurations; the large temperature gradient through the insulation in the middle of the wall can be observed in Fig. 7 .

Fig. 8 shows the heat fluctuations of an uninsulated wall with a southern orientation in Erzurum for an average day in January. Heat flux values exhibit a wide range when using the sandwich insulated wall type according to Fig. 9, which shows the heat storage per unit cross section area and heat conduction values through the sandwich wall insulation type in a residential building in Erzurum. The indoor air temperature was fixed at $20^{\circ} \mathrm{C}$, and the daily average of the January data was used as the outside condition. Insulation in the north-facing wall significantly reduced the heat flux and its fluctuations on the inside surface (Fig. 9).

The temperature distribution through an uninsulated wall is shown in Fig. 10 for the selected times of 06.00, 12.00, 18.00 and 24.00 during a day in July. The room air temperature is assumed to be $24^{\circ} \mathrm{C}$, and the temperature fluctuations on the inside surface of the uninsulated wall are fairly high: between 25.4 and $26.7^{\circ} \mathrm{C}$ for all insulation types.

Temperature distributions through a sandwich wall at 4 different times in a day in July using average daily data are shown in

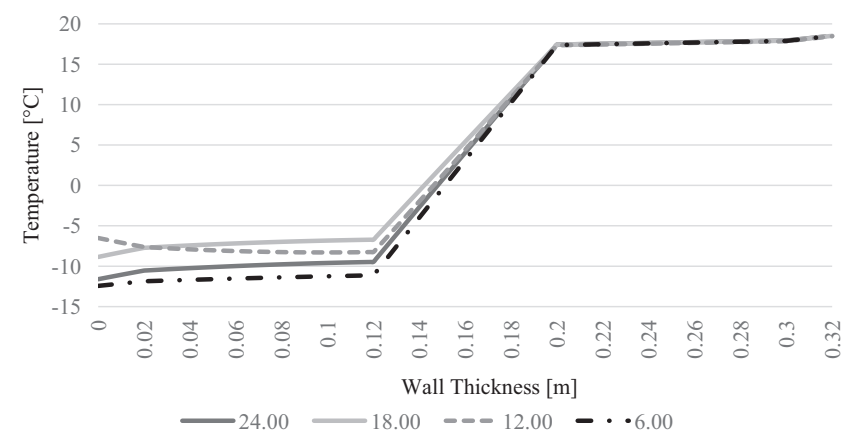

Fig. 7. Sandwich wall temperature distributions through the wall at different times of the day for a north-facing wall in January in Erzurum.

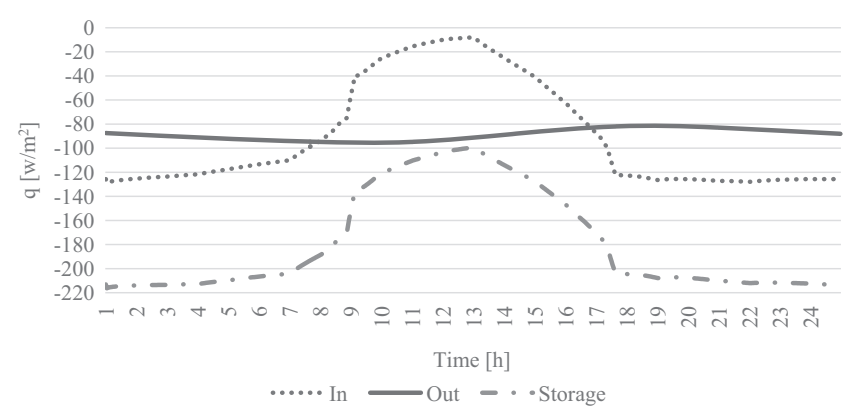

Fig. 8. Hourly variation of the storage energy and inside/outside surface heat transfer rates per unit surface area of a south-facing uninsulated wall structure for January in Erzurum. 
Fig. 11. The numerical solution provides the temperature distribution across the composite wall in a residential building in İzmir. In any building projected to function as a residence, sandwich wall thermal insulation should be selected for the exterior wall during the summer and winter months.

Fig. 12 shows the heat fluctuations of an uninsulated wall with a northern orientation based on daily average behavior in July in İzmir. For the numerical calculations, the indoor air temperature is assumed to be $24^{\circ} \mathrm{C}$, and meteorological data are used for the outside conditions. According to these calculations, significant heat gain from the inside surface to the inside environment occurs linearly during the day. A solar radiation effect is clearly seen in the morning and afternoon when sunlight strikes the north surface.

Fig. 13 shows the energy stored in the wall and the heat transfer rates from/to the wall per unit area in summer based on the worst case of heat gain value using July's monthly average daily data for a south-facing wall in İzmir. The heat gain from the inside surface denoted "Out" in Fig. 13 decreased significantly compared with the heat gain in Fig. 12, and the daily behavior of the heat gain is found to be nearly stable when sandwich wall insulation is used.

\subsection{Overall daily heat transfer based on varying U-values}

Following the parametric analysis, the charts in Figs. 14 and 15 show the solution of the one-dimensional transient heat conduction problem for a multi-layer building exterior wall combination and the performance parameters with insulation as well as the uninsulated wall possibilities related to the predicted energy usage of an exterior wall per square meter for different overall heat transfer coefficient values. The numerical calculations were repeated for different insulation thicknesses and for an uninsulated wall; the results were also compared with TS825 taken as a reference condition [18]. The scales at the left sides of Figs. 14 and 15 represent the ratio of heat transfer between different conditions mentioned on the right sides. The scales of the figures are arranged to show the results most clearly. Because the daily heat transfer per unit area for the uninsulated situation was significantly larger than the others, its scale is chosen as 10/1 in Figs. 14 and 15. In contrast, for the lowest $U$-value, the scale is decreased to $1 / 2$. The pie charts are drawn based on the TS825 configuration and the highest heat loss and gain, which are the Erzurum and İzmir cases. These cases were chosen to be $100 \%$, and the other pie charts were drawn based on these scales. The numbers below the pie charts are the approximate average values of the daily heat transfer per unit area using the four types of wall orientations. Each orientation percentage of the total values with standard deviations is also mentioned in Figs. 14 and 15 individually.

The heat loss from the north-facing exterior facades exhibit the highest percentage, whereas the south facade's loads exhibit the

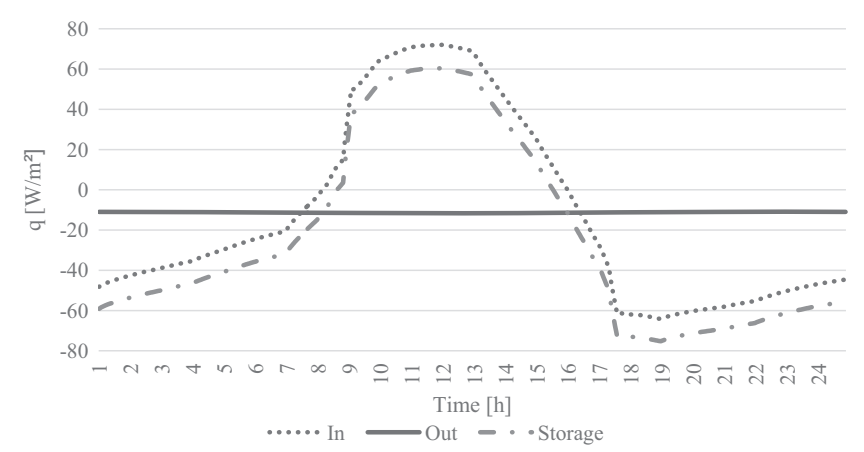

Fig. 9. Hourly variation of the storage energy and inside/outside surface heat transfer rates per unit surface area of a north-facing sandwich wall structure for January in Erzurum.

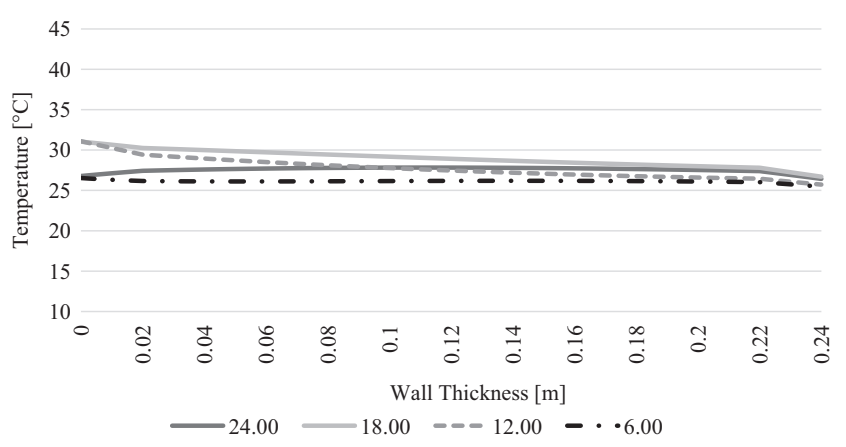

Fig. 10. Uninsulated wall temperature distribution through the wall at different times of the day for a north-facing wall in July in İzmir.

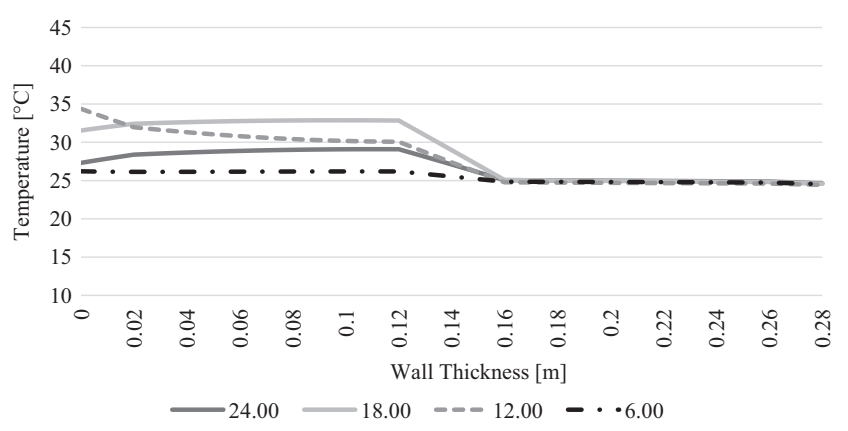

Fig. 11. Sandwich wall temperature distribution through the wall at different times of the day for a north-facing wall in July in İzmir.

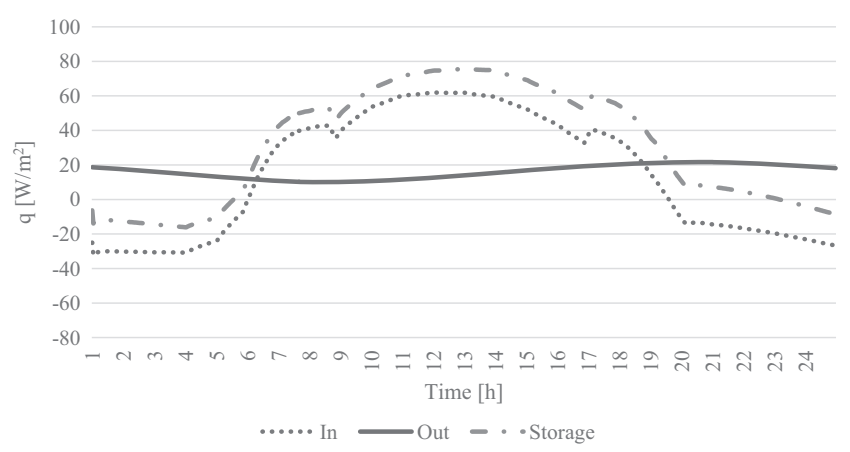

Fig. 12. Hourly variation of the storage energy and inside/outside surface heat transfer rates per unit surface area of a north-facing uninsulated wall structure for July in İzmir.

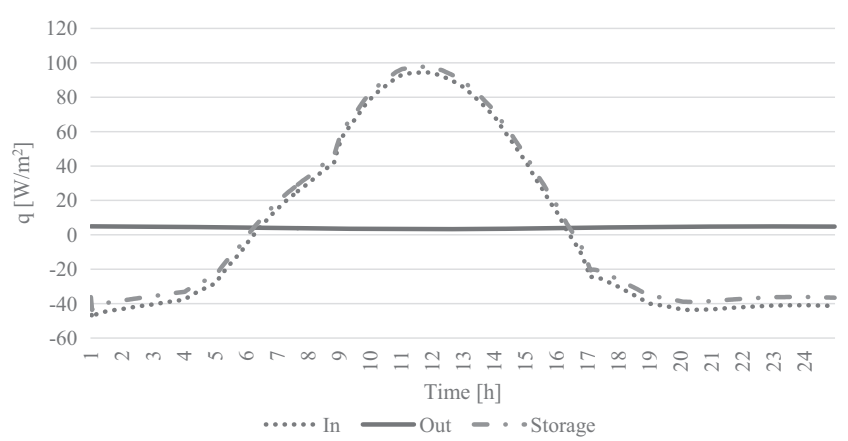

Fig. 13. Hourly variation of the storage energy and inside/outside surface heat transfer rates per unit surface area of a north-facing sandwich wall structure in July in İzmir. 


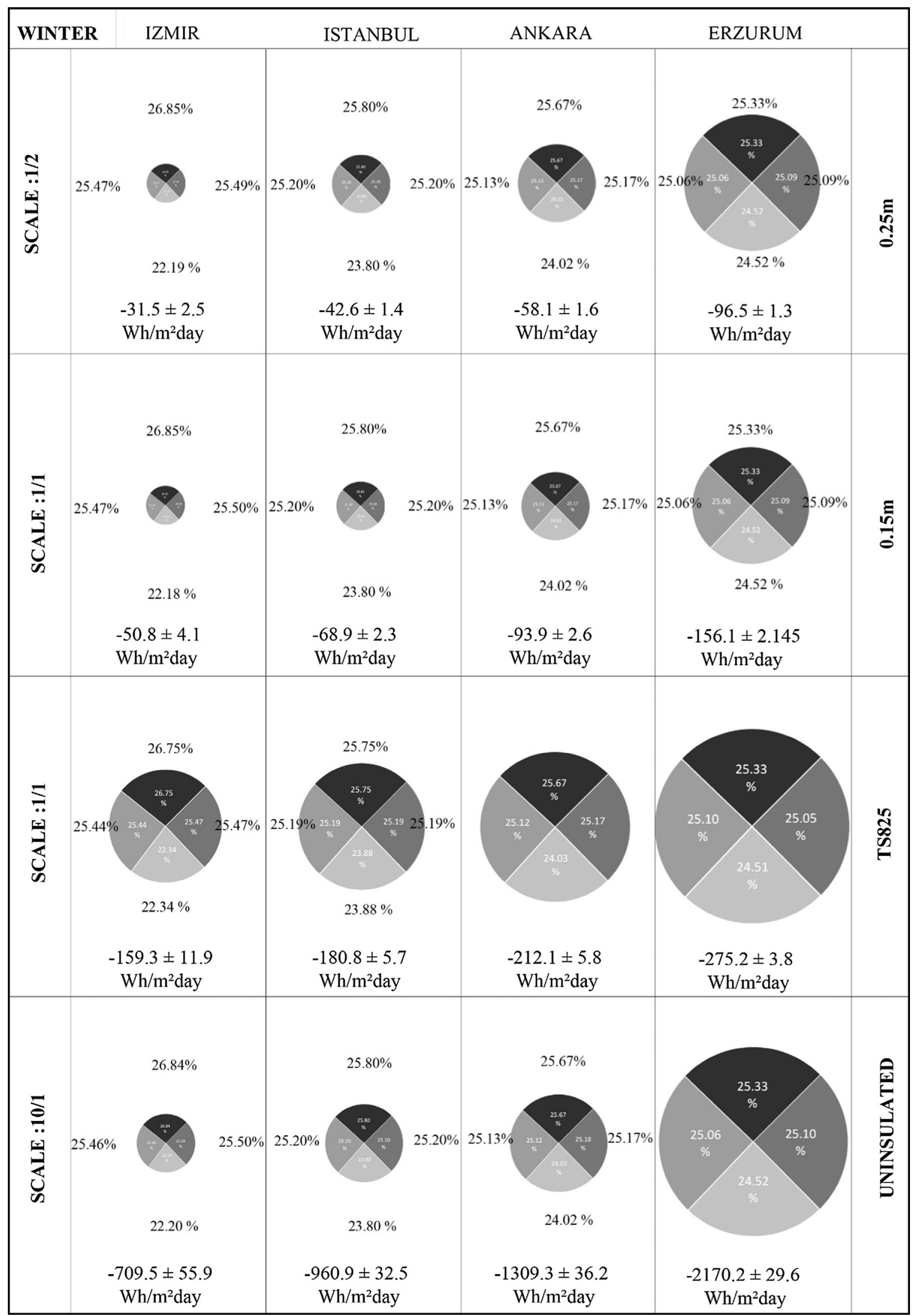

Fig. 14. Overall daily heat transfer per unit area under different climatic conditions and exterior wall compositions based on varying U-values in January.

lowest values for all wall structures and all climate conditions in winter as shown in Fig. 14. The highest heat gain values were calculated for the east- and west-facing exterior walls for all struc- tures and climates as shown in Fig. 15. From these figures, it can be observed that increasing the thickness of the insulation has a slight impact on heat gain and loss. According to the results shown 


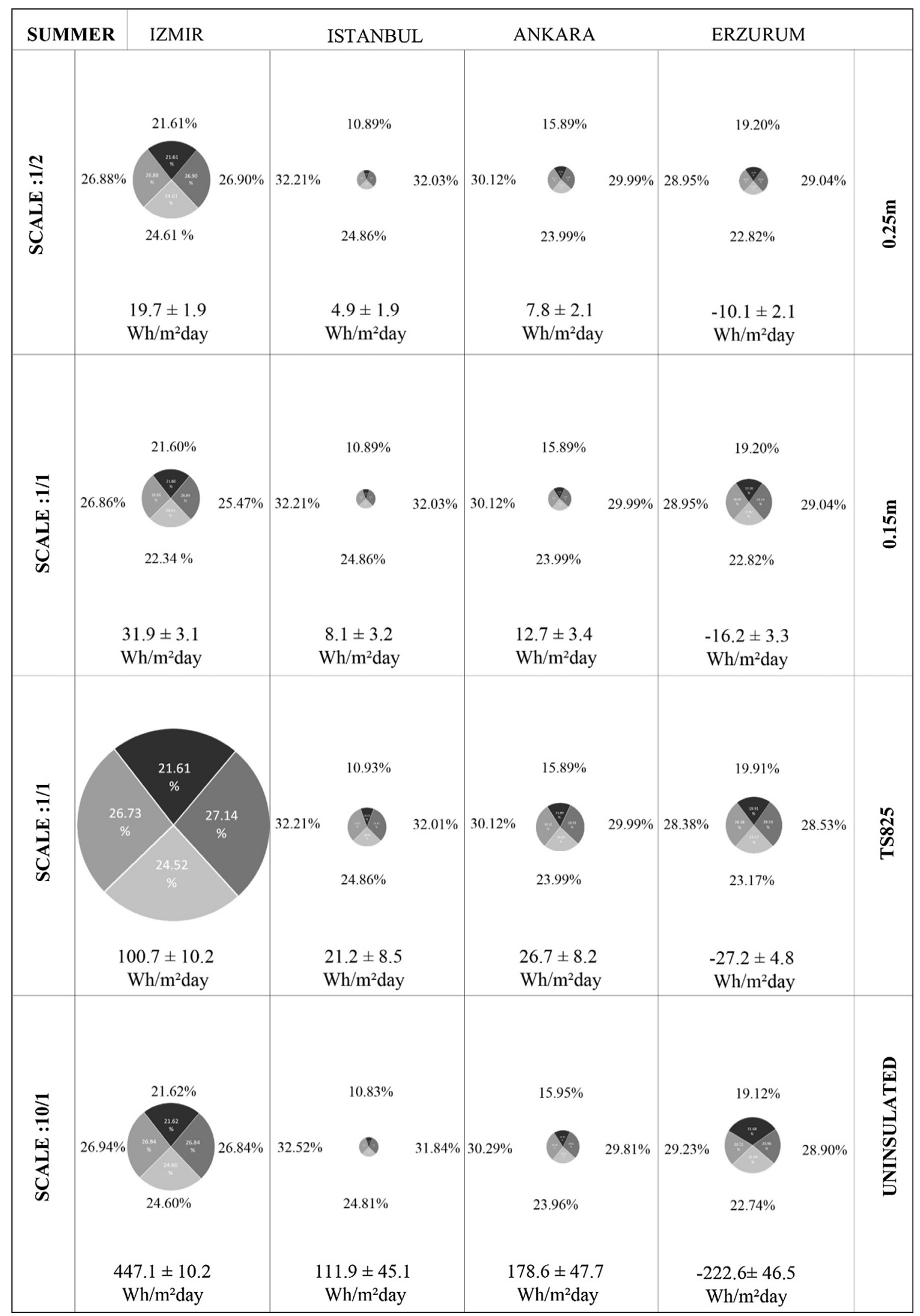

Fig. 15. Overall daily heat transfer per unit area under different climatic conditions and exterior wall compositions based on varying U-values in July.

in Figs. 14 and 15 , the $U$ values corresponding to the insulation thicknesses differ for the four different climates in the winter and summer in Turkey. These figures exemplify the effect of the insulation thickness when comparing the four configurations. A $0.15 \mathrm{~m}$ insulation thickness for the sandwich wall changes the results approximately three times less than the TS825 results, 
and a $0.25 \mathrm{~m}$ insulation thickness for the sandwich wall changes the results approximately five times less than the TS825 results. For example, in the Mediterranean climate in summer in İzmir, the south-facing wall's heat gain values are $19.43 \mathrm{Wh} / \mathrm{m}^{2}$ day, $31.46 \mathrm{~W} \mathrm{~h} / \mathrm{m}^{2}$ day and $98.76 \mathrm{~W} \mathrm{~h} / \mathrm{m}^{2}$ day for insulation thicknesses of $0.25 \mathrm{~m}, 0.15 \mathrm{~m}$ and $0.04 \mathrm{~m}$, respectively. In contrast, when considering the uninsulated condition, the heat gain can be decreased from $447.1 \mathrm{~W} \mathrm{~h} / \mathrm{m}^{2}$ day to $19.7 \mathrm{~W} \mathrm{~h} / \mathrm{m}^{2}$ day as average values. The highest heat loss values were obtained for the uninsulated condition in Erzurum, at approximately $-2170.2 \mathrm{~W} \mathrm{~h} / \mathrm{m}^{2}$ day; using different insulation thicknesses, the daily average heat loss values were decreased up to $-96.5 \mathrm{~W} \mathrm{~h} / \mathrm{m}^{2}$ day, $-156.1 \mathrm{~W} \mathrm{~h} / \mathrm{m}^{2}$ day and $275.2 \mathrm{Wh} / \mathrm{m}^{2}$ day for insulation thicknesses of $0.25 \mathrm{~m}, 0.15 \mathrm{~m}$ and $0.08 \mathrm{~m}$, respectively.

\section{Conclusion}

In this study, the one-dimensional transient heat conduction equation was solved via the implicit finite difference method with different climates for different orientations. The results indicate that the sandwich wall insulation type enables slightly lower energy consumption compared with exterior and interior wall insulation applications for residential usage for 24-h working conditions. Additionally, heat loss and gain values were significantly reduced with thicker insulation. These results depended on the direction of the opaque wall under winter and summer conditions in the different climates. On the other hand, since the thicker insulation covers more interior space, decision of the material selection of the exterior wall must be also analyzed economically.

The next step of the study will be to analyze the heat transfer through the exterior wall for different working hour conditions for education building and shopping center. The effect of insulation location with different heat capacity material usage and different orientations will provide valuable results in terms of energy saving under these conditions.

The results acquired in this time-dependent study will be helpful from energy conservation and thermal comfort points of view. They are expected to help reduce the capacities of heating and cooling systems and guide the choice of insulation type for building envelopes in different climates. In addition, wall orientation percentage given in this study will be also helpful for the interior unit capacity selection of the heating and cooling system.

\section{References}

[1] A. Bolattürk, Optimum insulation thicknesses for building walls with respect to cooling and heating degree-hours in the warmest zone of Turkey, Build. Environ. 43 (2008) 1055-1064.

[2] A. Ucar, Thermoeconomic analysis method for optimization of insulation thickness for the four different climatic regions of Turkey, Energy 35 (4) (2010) $1854-1864$.
[3] J. Yu, C. Yang, L. Tian, D. Liao, A study on optimum insulation thicknesses of external walls in hot summer and cold winter zone of China, Appl. Energy 86 (2009) 2520-2529.

[4] Ö.A. Dombaycı, M. Gölcü, Y. Pancar, Optimization of insulation thickness for external walls using different energy-sources, Appl. Energy 83 (2006) 921928.

[5] M. Kayfeci, A. Keçebaş, E. Gedik, Determination of optimum insulation thickness of external walls with two different methods in cooling applications, Appl. Therm. Eng. 50 (2013) 217-224.

[6] M. Ozel, K. Prhtılı, Determination of optimum insulation thickness by using heating and cooling degree-day values, Int. J. Eng. Natl. Sci. (2008) 191-197.

[7] K. Comaklı, B. Yüksel, Optimum insulation thickness of external walls for energy saving, Appl. Therm. Eng. 23 (2003) 473-479.

[8] N. Daouas, Z. Hassen, H. Aissa, Analytical periodic solution for the study of thermal performance and optimum insulation thickness of building walls in Tunisia, Appl. Therm. Eng. 30 (2010) 319-326.

[9] R. Yumrutaş, Ö. Kaşka, E. Yıldırım, Estimation of total equivalent temperature difference values for multilayer walls and flat roofs by using periodic solution, Build. Environ. 42 (2007) 1878-1885.

[10] S.A. Al-Sanea, F. Zedan, Effect of insulation location on thermal performance of building walls under steady periodic conditions, Int. J. Ambient Energy 22 (2011) 59-72.

[11] M. Ozel, Effect of insulation location on dynamic heat-transfer characteristics of building external walls and optimization of insulation thickness, Energy Build. 72 (2014) 288-295.

[12] M. Ozel, Thermal performance and optimum insulation thickness of building walls with different structure materials, Appl. Therm. Eng. 31 (2011) 38543863.

[13] M. Ibrahim, P. Biwole, E. Wurtz, P. Achard, A study on the thermal performance of exterior walls covered with a recently patented silica-aerogel-based insulating coating, Build Environ. 81 (2014) 112-122.

[14] A. Gagliano, F. Patania, F. Nocera, C. Signorello, Assessment of the dynamic thermal performance of massive buildings, Energy Build. 72 (2014) 361-370.

[15] T. Başaran, Thermal analysis of the domed vernacular houses of Harran, Turkey, Indoor Built Environ. 20 (2011) 543-554.

[16] I. Axaopoulos, P. Axaopoulos, J. Gelegenis, Optimum insulation thickness for external walls on different orientations considering the speed and direction of the wind, Appl. Energy 117 (2014) 167-175.

[17] E. Wati, P. Meukam, M.K. Nematchoua, Influence of external shading on optimum insulation thickness of building walls in a tropical region, Appl. Therm. Eng. 90 (2015) 754-762.

[18] Turkish Standards Institution, TS825: Thermal Insulation Requirements for Buildings, Ankara, 2013.

[19] State Meteorological Station, Records for Weather Data (2000-2010) Turkey.

[20] PVPS, IEA, Evaluation of Islanding Detection Methods for Photovoltaic Utility Interactive Power Systems, Report IEA PVPS T5-09, 2002.

[21] D. Olivier, The carbonlite energy performance standards, in: AECB 15th Conference, 2008.

[22] ASHRAE, ANSI/ASHRAE Standard 55-2010: Thermal Environment Conditions for Human Occupancy, American Society of Heating, Ventilation and Air Conditioning Engineers, Atlanta, GA, 2014.

[23] M. Šuri, T.A. Huld, E.D. Dunlop, H.A. Ossenbrink, Potential of solar electricity generation in the European Union member states and candidate countries, Sol. Energy 81 (2007) 1295-1305.

[24] GRASS (Geographic Resources Analysis Support System) GIS, 2006.

[25] ESRA (European Solar Radiation Atlas), fourth ed., published for the Commission of the European Communities by Presses de l'Ecole des Mines de Paris, Paris, France, 2000.

[26] J.A. Duffie, W.A. Beckman, Solar Engineering of Thermal Processes, Wiley, New York etc, 1980.

[27] T. Pekdoğan, An investigation of Transient Thermal Behaviors of Building External Walls (Unpublished Master's Thesis), İzmir Institute of Technology, İzmir, 2015. 